\title{
Detection of HIV-1 dual infections in highly exposed treated patients
}

\author{
Guadalupe Andreani ${ }^{1 \dagger}$, Constanza Espada ${ }^{1 \dagger}$, Ana Ceballos ${ }^{1 \dagger}$, Juan Ambrosioni ${ }^{1}$, Alejandro Petroni ${ }^{2}$, Dora Pugliese ${ }^{2}$, \\ María Belén Bouzas ${ }^{3}$, Silvia Fernandez Giuliano ${ }^{3}$, Mercedes C Weissenbacher ${ }^{1}$, Marcelo Losso ${ }^{4}$, Jorge Benetucci ${ }^{2}$, \\ Jean K Carr ${ }^{5}$ and Liliana Martínez Peralta ${ }^{*^{*}}$
}

\begin{abstract}
Background: Genetic characterization of HIV-1 in Argentina has shown that BF recombinants predominate among heterosexuals and injecting drug users, while in men who have sex with men the most prevalent form is subtype B.

Objectives: The aim of this work was to investigate the presence of HIV dual infections in HIV-infected individuals with high probability of reinfection

Study design: Blood samples were collected from 23 HIV positive patients with the risk of reinfection from Buenos Aires. A fragment of the HIV gene pol was amplified and phylogenetic analyses were performed. Antiretroviral drug resistance patterns of all the sequences were analyzed.

Results: Five dual infections were detected with four patients coinfected with subtype B and BF recombinants and one patient was coinfected with two BF recombinants presenting different recombination patterns. Prolonged infection with a stable clinical condition was observed in the five individuals. Resistance mutation patterns were different between the predominant and the minority strains.
\end{abstract}

Conclusions: Our results show that HIV dual infection can occur with closely related subtypes, and even with different variants of the same recombinant form in certain populations. Clinical observations showed neither aggressive disease progression nor impact on the resistance patterns in the dually-infected patients.

\section{Findings}

The occurrence of infection with more than one strain of HIV-1 has important implications for understanding HIV transmission and for the development of an AIDS vaccine, as well as the fact that it is leading to many recombinant strains of global epidemiological relevance [1-3].

Resistance concerns also emerged as a key issue for dually infected patients, since they can acquire a resistant strain or generate a multidrug-resistant virus [4]. Nevertheless, the influence of superinfection on resistance evolution is still unclear [5].

\footnotetext{
* Correspondence: lilimp@fmed.uba.ar

† Contributed equally

${ }^{1}$ National Reference Center for AIDS, Microbiology Department, (Paraguay

2155), School of Medicine, University of Buenos Aires, Buenos Aires,

(C1121ABG), Argentina

Full list of author information is available at the end of the article
}

The genetic characterization of HIV-1 in Argentina showed that BF recombinant forms are the most prevalent genetic forms among heterosexuals, and among intravenous drug users (IDUs); while subtype B is the most prevalent in men who have sex with men (MSM) [6-8]. Thus, patients with multiple epidemiological risks (e.g. bisexual men and/or IDUs) may be exposed to both subtype $B$ and BF recombinants.

To evaluate the presence of HIV-1 dual infections we selected HIV-1 positive individuals whom presented multiple epidemiological risks for HIV-1 infection, based on confidential interviews regarding sexual behavior, intravenous drug use and medical history, in Buenos Aires, Argentina. Informed consent was obtained from all individuals. Blood samples were collected and serological studies were performed. Total RNA and genomic DNA isolation from plasma and PBMC respectively were performed, (QIAgen, Valencia, CA, USA). A pol 
gene fragment was amplified as described [9], and cloned into the pCR2.1-Topo vector (Invitrogen) or evaluate by single genome amplification (SGA) [9]. The amplicons were then sequenced with Big Dye terminators using an ABI 3100 automated sequencer (Applied Biosystems Inc, Foster City CA). Drug resistance phenotype was determined using the Stanford University HIV Drug Resistance. Sequence alignment was performed using the CLUSTAL $\times$ software, followed by a Neighbor-joining method with Kimura's two-parameter model of distance calculation using MEGA 4.1. Recombinant analysis was performed using SimPlot v2.5

For case 1 (C1), a dual infection was found in the first sample (C1S1), where 1 out of 21 clones clustered with $\mathrm{BF}$ recombinants and the rest with subtype $\mathrm{B}$. The recombinant $\mathrm{BF}$ clone exhibited a different pol gene recombination pattern than CRF12_BF. However, in C1S2 (2 years later) all of the 12 clones clustered with subtype $B$ references (Figure 1a). The mean of the genetic distances of the $\mathrm{B}$ sequences from $\mathrm{C} 1 \mathrm{~S} 1 \mathrm{com}-$ pared to those from $\mathrm{C} 1 \mathrm{~S} 2$ was $2 \%$, while their distance to other Argentine subtype B sequences was close to
$5 \%$, suggesting that C1S2 sequences did not occur due to a new superinfection. This patient was diagnosed in September 1991 and until the sampling period has been asymptomatic. He reported having had heterosexual contacts but for the last 10 years he has only had homosexual intercourse. He had been receiving antiretroviral (ARV) treatment since 1995 (Table 1). The analysis of resistance pattern showed that there were relevant resistance mutations in the RT (Table 2).

In the only sample available from $\mathrm{C} 2,1$ out of 25 sequenced clones clustered with subtype $B$ while the others clustered with BF recombinants (Figure $1 \mathrm{~b}$ ). The BF clones exhibited a similar pol gene recombination pattern to CRF12_BF (Figure 1b). This patient was diagnosed in January 2000 and reported having had only homosexual encounters, with some male partners being foreigners and/or HIV-infected. He had no resistance mutations in the BF clones, but subtype $\mathrm{B}$ sequence showed major PI resistance mutations (Table 2).

In $\mathrm{C} 3$, two sequences clustered with the CRF12_ BF, while 13 grouped with $B$ references (Figure 2a). HIV infection was diagnosed in 2000 and the patient

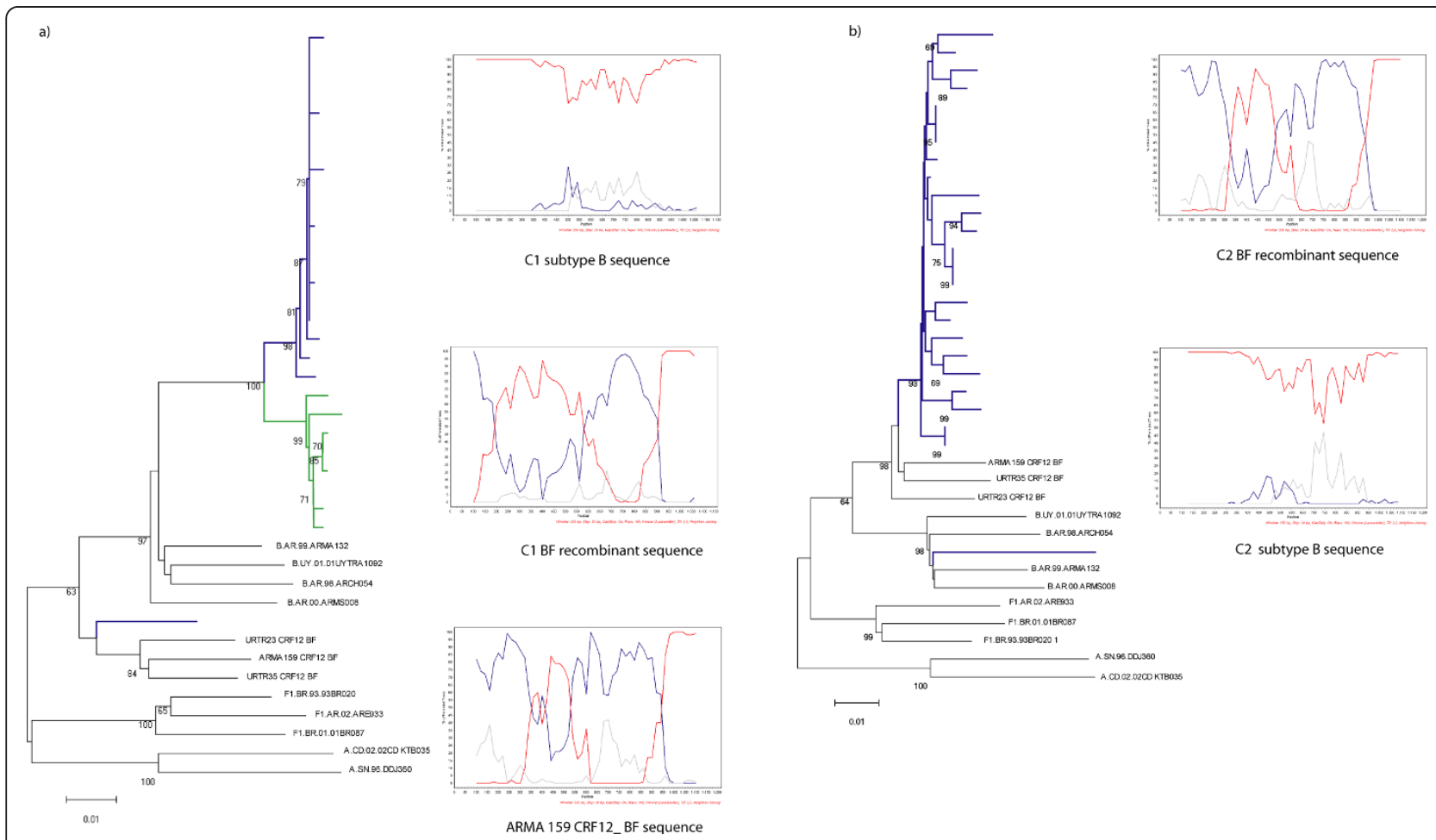

Figure $1 \mathrm{NJ}$ phylogenetic tree and bootscanning analysis of HIV-1 pol region from the sequences of HIV-1 positive individuals with evidence of dual infection. The trees were constructed with the NJ method and Kimura two-parameter model (ts/tv $=2 / 1$ ) and they were performed with the complete fragment analyzed. Bootstrap values (1000 resamples) higher than 60 and scale are shown. Bootscanning analysis was performed comparing the sample with the reference sequences: HXB2; WR27, MN and RL42 (subtype B: red line); BR020, V1850, FIN9363 (subtype F: blue line), and U455, SE7253, 92 UG037 (subtype A: grey line). A 200 nt window advanced in 20 nt increments was used by the NJ method and Kimura two-parameter model $(\mathrm{ts} / \mathrm{tv}=2 / 1)$. a) Case $1 ;$ b) Case 2 . Sequences from sample 1 are indicated with blue lines while the sequences from sample 2 are in green. 
Table 1 Clinical data from 5 HIV-1 dual infected individuals

\begin{tabular}{|c|c|c|c|c|c|c|}
\hline Case & Institution & Risk category & Time points & CD4 (cells/ $\mu \mathrm{l})$ & VL (RNA copies/ml plasma) & HAART* \\
\hline \multirow[t]{2}{*}{1} & R. Mejia Hospital & Bisexual male & S1 & NA & $2,5 \times 10^{4}$ & d4T 3TC EFV (failure) \\
\hline & & & S2 & & $3,3 \times 10^{5}$ & ddl ZDV SQV/r (failure) \\
\hline 2 & R. Mejia Hospital & Bisexual male & Unique sample & NA & 446 & No \\
\hline 3 & FUNDAI & Bisexual male & Unique sample & $>400$ & $<50$ & ZDV 3TC EFV (effective) \\
\hline \multirow[t]{2}{*}{4} & FUNDAI & Bisexual male- IDU & S1 & 447 & $5,7 \times 10^{4}$ & No \\
\hline & & & S2 & 905 & $8,2 \times 10^{4}$ & \\
\hline \multirow[t]{2}{*}{5} & FUNDAI & IDU & S1 & 453 & NA & ddl D4T NVP** \\
\hline & & & S2 & 497 & $1,2 \times 10^{4}$ & \\
\hline
\end{tabular}

* At the moment of dual infection detection.

** This treatment was two years before sampling.

NA: not available.

declared having had sexual intercourse with members of both sexes. This patient discontinued his treatment without medical indication. But during the sampling period (2004) he was again on HAART and clinically asymptomatic (Table 1 ).

In C4S1, 20 sequences were obtained from DNA and amplified by SGA and 11 clones from RNA. As shown, one sequence derived from DNA clustered with subtype B references while 19 clustered with CRF12_ BF references (Figure 2b). Recombination as well as similarity to the CRF12_BF was confirmed (Figure 2b). In C4S2, 22 clones clustered with CRF12_BF references. The HIV infection was diagnosed in 1993. Fifteen years prior to the sample collection, he conceded to having had sexual intercourse with men, with only heterosexual relations thereafter. His female partner was an IDU HIV+ and she was also coinfected with $\mathrm{HCV}$ and $\mathrm{HBV}$. The patient was clinically asymptomatic during sampling and had never been on HAART (Table 1).

In C5S1, all the sequences clustered with the CRF12_BF with a high bootstrap value (Figure B.e). In C5S2, besides proviral DNA, RNA was also analyzed by cloning. One sequence from S2 amplified by SGA clustered with a BF recombinant showing a different recombination pattern confirmed by bootscanning analysis (Figure 2c). The NJ tree showed that sequences from both samples formed one cluster. HIV infection in this patient was diagnosed in 1998. He reported being an IDU as his only risk factor and was coinfected with HCV. He had always had high CD4 T-cell counts and was clinically asymptomatic at the time of the study (Table 1). He had received HAART therapy but he

Table 2 Evolution of antiretroviral resistance mutations in HIV-1 individuals with dual infections

\begin{tabular}{|c|c|c|c|c|c|}
\hline \multirow[t]{2}{*}{ Case } & \multirow[t]{2}{*}{ Time points } & \multicolumn{2}{|c|}{ Primary subtype } & \multicolumn{2}{|c|}{ Secondary subtype } \\
\hline & & Prot & RT & Prot & RT \\
\hline \multirow[t]{3}{*}{$\mathrm{C} 1$} & & \multicolumn{2}{|c|}{ B subtype } & \multicolumn{2}{|c|}{ BF recombinant (not CRF12) } \\
\hline & S1 & NONE & $\begin{array}{c}\text { M41L/M184V/Y188L/L210W/T215Y21 } \\
\text { V1061, H221Y and D67N (A) }\end{array}$ & NONE & NONE \\
\hline & S2 & $\begin{array}{c}\text { L10I//15V/M46I/L63P/I84V/I85V/L90M }{ }^{12} \\
\text { M36l and F53L/A71T T(A) }\end{array}$ & M41L/D67N/L210W/T215Y'12 & & NON DETECTED \\
\hline \multirow[t]{2}{*}{$\mathrm{C} 2$} & & \multicolumn{2}{|c|}{ CRF12_BF } & \multicolumn{2}{|r|}{ B subtype } \\
\hline & & NONE & NONE & I84V/L90M & M41L/K70E/L210W/T215Y \\
\hline \multirow[t]{2}{*}{$\mathrm{C3}$} & & \multicolumn{2}{|c|}{ B subtype } & \multicolumn{2}{|r|}{ CRF12_BF } \\
\hline & & NONE & $\mathrm{K} 103 \mathrm{~N}^{1}$ & NONE & NONE \\
\hline \multirow[t]{3}{*}{ C4 } & & \multicolumn{2}{|c|}{ CRF12_BF } & \multicolumn{2}{|r|}{ B subtype } \\
\hline & S1 & $147 V^{1}$ & NONE & NONE & NONE \\
\hline & S2 & NONE & K70R' & & NON DETECTED \\
\hline \multirow[t]{3}{*}{ C5 } & & \multicolumn{2}{|c|}{ CRF12_BF } & \multicolumn{2}{|c|}{ BF recombinant (not CRF12) } \\
\hline & S1 & NONE & $\mathrm{Y} 181 \mathrm{C} / \mathrm{H} 221 \mathrm{Y}^{2}$ & \multicolumn{2}{|r|}{ NON DETECTED } \\
\hline & S2 & NONE & Y181C ${ }^{1}$ & NONE & NONE \\
\hline
\end{tabular}

A mean of sixteen sequences and/or clones per sample were analyzed with Stanford software. Resistance mutations separeted by bars indicate combination of mutations in the sequences. The number indicated by superscript shows the number of sequences or clones with the corresponding mutation or combination of mutations.

(A) Each mutation in different sequences and carrying the combination of mutations indicated. 


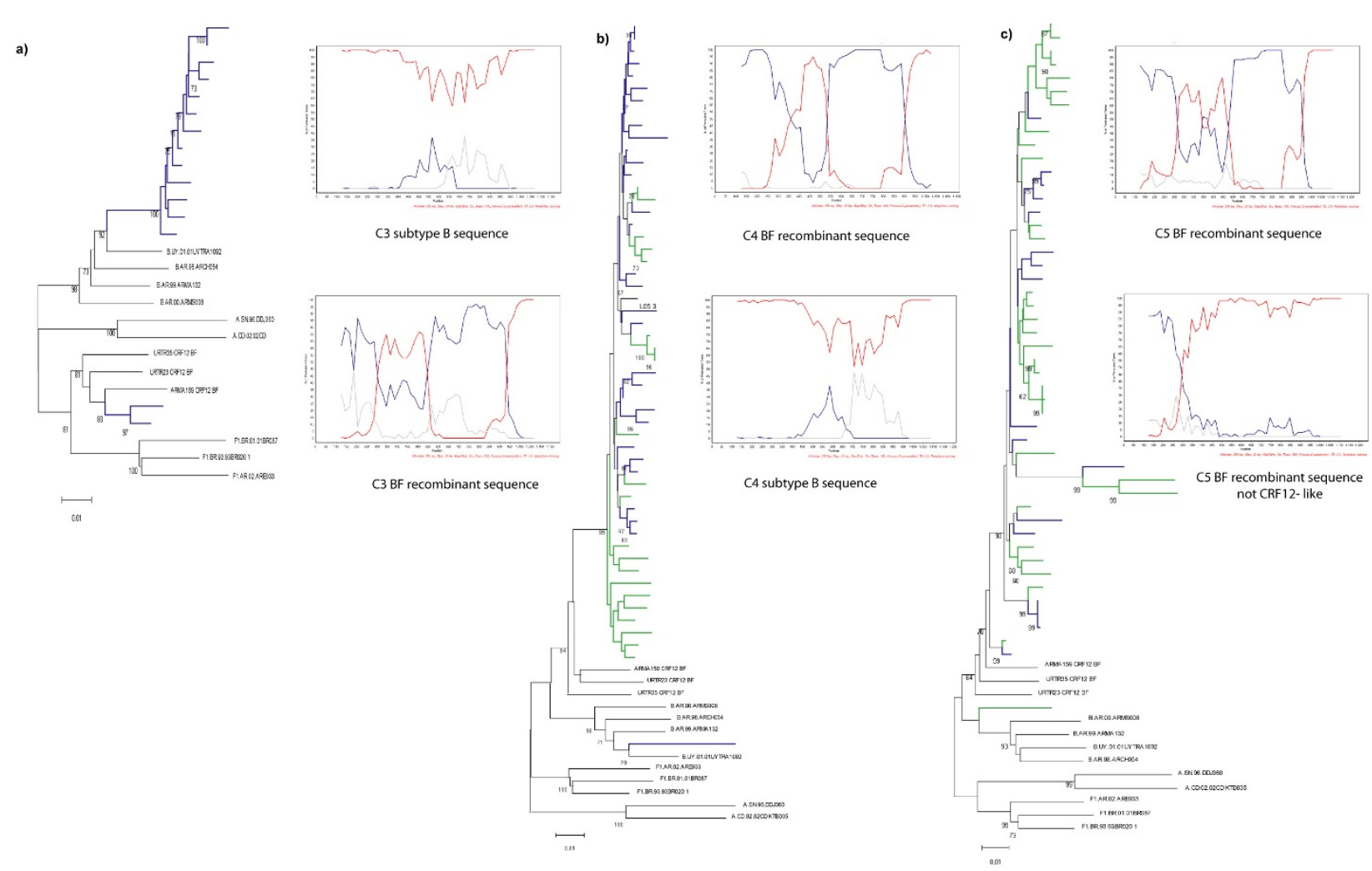

Figure $2 \mathrm{NJ}$ phylogenetic tree and bootscanning analysis of HIV-1 pol region from the sequences of HIV-1 positive individuals with evidence of dual infection. The trees were constructed with the NJ method and Kimura two-parameter model (ts/tv = 2/1) and they were performed with the complete fragment analyzed. Bootstrap values (1000 resamples) higher than 60 and scale are shown. Bootscanning analysis was performed comparing the sample with the reference sequences: HXB2; WR27, MN and RL42 (subtype B: red line); BR020, VI850, FIN9363 (subtype F: blue line), and U455, SE7253, 92 UG037 (subtype A: grey line). A 200 nt window advanced in 20 nt increments was used by the NJ method and Kimura two-parameter model (ts/tv = 2/1). a) Case 3; b) Case 4; c) Case 5. Sequences from sample 1 are indicated with blue lines while the sequences from sample 2 are in green.

interrupted it two years before the first sample was taken (Table 2).

It has been observed that several drug resistance-associated mutations in the pol region of BF recombinant variants include mutations which are in fact natural polymorphisms of the BF strains $[10,11]$. Therefore, we only considered major PI-resistance associated mutations to categorize viral variants as resistant. Among the $\mathrm{B}$ sequences in $\mathrm{C} 1$, there were multiple resistance mutations to NRTI and NNRTI, but the unique BF sequence was susceptible. Hence, the selective pressure of the treatment could be responsible for the predominance of subtype B [12]. Moreover, the changes in the resistance patterns from $\mathrm{C} 1 \mathrm{~S} 1$ to $\mathrm{C} 1 \mathrm{~S} 2$ completely mirrored the treatment change (Tables 1 and 2). The fitness costs on the persistence of $\mathrm{M} 184 \mathrm{~V}$ in the absence of selective pressure has been extensively studied [13] and it has been observed that viruses carrying the TAMs M41L, L210W and T215Y have higher fitness than those with M184V [14]. Therefore, between C1S1 and C1S2,
M184V did not persist in the viral population, while the TAMs did. A similar rationale can support the loss of NNRTI resistance-associated mutations. Finally, since the presence of at least three TAMs is associated with cross-resistance to ddI [14], the new HAART scheme actually worked as monotherapy leading to the selection of multiple PI resistance-associated mutations.

In $\mathrm{C} 2$, although he had never received ARV therapy, subtype $B$ strain clone was drug-resistant. This virus could have been acquired from a person with a resistant strain, and thus become the minority one because of its lower fitness [15]. Also, in C4 only one sequence from C4S1 carried a mutation to PR while one sequence from $\mathrm{C} 4 \mathrm{~S} 2$ had one mutation to RT. Since C4 had never received ART, these minority viral quasispecies might have disappeared. The evolution of his HIV disease had not been aggressive over time, but the RNA and proviral DNA sequences from $\mathrm{C} 4 \mathrm{~S} 1$ intermingled among the proviral sequences from S2, indicating active replication [16]. 
HIV-1 superinfections have been described after treatment interruption, as in C3, the minority CRF12_BF virus did not show any resistance mutations, it could be hypothesized that it might have been acquired after treatment interruption [17] (Table 2).

C5 had been under HAART, but treatment had been suspended due to medical advice. As with $\mathrm{C} 4$, active replication was observed [16]. The putative superinfection was likely coincidental with the relapse of intravenous drug use; which may explain the fact that the secondary virus was a BF recombinant, since these are common among IDUs [7]. Previous HAART probably explains the resistance mutations found in sequences of the predominant virus. Since the secondary viral sequence did not show any resistance mutations, as in C3, treatment interruption might have been a major predisposing factor leading to superinfection [17]. This individual could have acquired the second infection at least 8 years after the first one. In this regard, recent studies have found lack of protection against superinfection in chronic HIV-infected individuals as well as no significant deficits in neutralizing antibodies response [18]. In C5, the evaluation of the recombination patterns of each sequence and the analysis of partial trees performed taking into account the breakpoint of the superinfecting strain, suggest that, to the best of our knowledge, this is the first case of HIV dual-infection with different BF recombinants (Figure $2 \mathrm{c}$ and data not shown).

The link between dual infection and recombinant forms has been already shown $[19,20]$, and since a high viral load level is important in transmission, it could be that recombinants are generated in individuals who also develop higher viral loads and readily transmit them. Eventually, superinfection and double infection would be expected to increase the complexity of viral genotypes circulating in the population $[21,22]$.

In this report, we described five cases of dual infections from 23 individuals with multiple epidemiological risks. This study underlines the frequency of dual infection in high risk populations, but additional research will be needed to interpret superinfection in the context of anti-HIV-1 immunity and vaccine development.

\footnotetext{
Acknowledgements

This research has been partially funded by a Fogarty International Center/ $\mathrm{NIH}$ grant through the AIDS International Training and Research Program at Mount Sinai School of Medicine-Argentina Program (Grant \# 5D43 TW0010137) and grants from the University of Buenos Aires (M043) and the National Agency for Promotion of Science and Technology (PICT 200701021) to Liliana Martínez Peralta. Ana Ceballos was the recipient of a Rotary Scholarship. We would like to thank Lindsay Eyzaguirre for her help and all individuals for their participation.
}

\section{Author details}

${ }^{1}$ National Reference Center for AIDS, Microbiology Department, (Paraguay 2155), School of Medicine, University of Buenos Aires, Buenos Aires, (C1121ABG), Argentina. 'Laboratorio de Retrovirus, Fundación de Ayuda al Inmunodeficiente (FUNDAI), (Uspallata 2272), Buenos Aires, (C1282AEN), Argentina. ${ }^{3}$ Virology Section. Francisco Javier Muñiz, Infectious Diseases Hospital, (Uspallata 2272), Buenos Aires, (C1282AEN), Argentina. ${ }^{4}$ Servicio de Inmusuprimidos, Ramos Mejia Hospital, (Urquiza 609), Buenos Aires, (C1221ADC), Argentina. ${ }^{5}$ St James School of Medicine, (Lake Albert Rd), The Quarter, (A-1 2640), Anguilla.

\section{Authors' contributions}

$G A, C E$ and $A C$ were equally responsible for the design, cloning, viral characterization, and writing of the manuscript. JA, AP, and JKC were responsible for viral characterization and resistance studies. DP, MBB, SG, MW, ML and JB were responsible for the clinical data from patients. LMP was responsible for the design and writing of the manuscript. All authors read and approved the final manuscript.

\section{Competing interests}

The authors declare that they have no competing interests.

Received: 23 June 2011 Accepted: 8 August 2011

Published: 8 August 2011

\section{References}

1. van der Kuyl AC, Cornelissen M: Identifying HIV-1 dual infections. Retrovirology 2007, 4:67.

2. Blick G, Kagan RM, Coakley E, Petropoulos C, Maroldo L, GreigerZanlungo P, Gretz S, Garton T: The probable source of both the primary multidrug-resistant (MDR) HIV-1 strain found in a patient with rapid progression to AIDS and a second recombinant MDR strain found in a chronically HIV-1-infected patient. J Infect Dis 2007, 195:1250-1259.

3. Pernas M, Casado C, Fuentes R, Perez-Elias MJ, Lopez-Galindez C: A dual superinfection and recombination within HIV-1 subtype B 12 years after primoinfection. J Acquir Immune Defic Syndr 2006, 42:12-18.

4. Smith DM, Wong JK, Hightower GK, Ignacio CC, Koelsch KK, Petropoulos CJ, Richman DD, Little SJ: HIV drug resistance acquired through superinfection. Aids 2005, 19:1251-1256.

5. Leontiev W, Maury WJ, Hadany L: Drug induced superinfection in HIV and the evolution of drug resistance. Infect Genet Evol 2008, 8:40-50.

6. Avila MM, Pando MA, Carrion G, Peralta LM, Salomon H, Carrillo MG, Sanchez J, Maulen S, Hierholzer J, Marinello M, et al: Two HIV-1 epidemics in Argentina: different genetic subtypes associated with different risk groups. J Acquir Immune Defic Syndr 2002, 29:422-426.

7. Espinosa A, Vignoles M, Carrillo MG, Sheppard H, Donovan R, Peralta LM, Rossi D, Radulich G, Salomon H, Weissenbacher M: Intersubtype BF recombinants of HIV-1 in a population of injecting drug users in Argentina. J Acquir Immune Defic Syndr 2004, 36:630-636.

8. Segura M, Sosa Estani S, Marone R, Bautista CT, Pando MA, Eyzaguirre L, Sanchez JL, Carr JK, Montano SM, Weissenbacher M, Avila MM: Buenos Aires cohort of men who have sex with men: prevalence, incidence, risk factors, and molecular genotyping of HIV type 1. AIDS Res Hum Retroviruses 2007, 23:1322-1329.

9. Carr JK, Nadai Y, Eyzaguirre L, Saad MD, Khakimov MM, Yakubov SK, Birx DL, Graham RR, Wolfe ND, Earhart KC, Sanchez JL: Outbreak of a West African recombinant of HIV-1 in Tashkent, Uzbekistan. J Acquir Immune Defic Syndr 2005, 39:570-575.

10. Petroni AD, Gabriel , Pryluka D, Rotryng F, Bortolozzi R, Lopardo G, Bouzas MB, Zapiola I, Garone D, Rodríguez C, Chiocconi E, Lázaro ME, Murano F, Maranzana A, Oliva SM, Aparicio M, Beltrán M, Benetucci J: Update on Primary HIV-1 Resistance in Argentina: Emergence of Mutations Conferring High-Level Resistance to Nonnucleoside Reverse Transcriptase Inhibitors in Drug-Naive Patients. JAIDS 2006, 42:506-510.

11. Carobene MG, Rubio AE, Carrillo MG, Maligne GE, Kijak GH, Quarleri JF, Salomon $\mathrm{H}$ : Differences in frequencies of drug resistance-associated mutations in the HIV-1 pol gene of B subtype and BF intersubtype recombinant samples. J Acquir Immune Defic Syndr 2004, 35:207-209.

12. Prado JG, Parkin NT, Clotet B, Ruiz L, Martinez-Picado J: HIV type 1 fitness evolution in antiretroviral-experienced patients with sustained CD4+ $T$ cell counts but persistent virologic failure. Clin Infect Dis 2005, 41:729-737. 
13. Gallant JE: The M184V mutation: what it does, how to prevent it, and what to do with it when it's there. AIDS Read 2006, 16:556-559.

14. Johnson VA, Brun-Vezinet F, Clotet B, Gunthard HF, Kuritzkes DR, Pillay D, Schapiro JM, Richman DD: Update of the drug resistance mutations in HIV-1: December 2009. Top HIV Med 2009, 17:138-145.

15. Paredes R, Sagar M, Marconi VC, Hoh R, Martin JN, Parkin NT, Petropoulos CJ, Deeks SG, Kuritzkes DR: In vivo fitness cost of the M184V mutation in multidrug-resistant human immunodeficiency virus type 1 in the absence of lamivudine. J Virol 2009, 83:2038-2043.

16. Casado C, Garcia S, Rodriguez C, del Romero J, Bello G, Lopez-Galindez C: Different evolutionary patterns are found within human immunodeficiency virus type 1-infected patients. J Gen Virol 2001, 82:2495-2508.

17. Ramos A, Hu DJ, Nguyen L, Phan KO, Vanichseni S, Promadej N Choopanya K, Callahan M, Young NL, McNicholl J, et al: Intersubtype human immunodeficiency virus type 1 superinfection following seroconversion to primary infection in two injection drug users. J Virol 2002, 76:7444-7452.

18. Piantadosi A, Chohan B, Chohan V, McClelland RS, Overbaugh J: Chronic HIV-1 infection frequently fails to protect against superinfection. PLOS Pathog 2007, 3:e177.

19. Fang G, Weiser B, Kuiken C, Philpott SM, Rowland-Jones S, Plummer F, Kimani J, Shi B, Kaul R, Bwayo J, et al: Recombination following superinfection by HIV-1. Aids 2004, 18:153-159.

20. Jurriaans S, Kozaczynska K, Zorgdrager F, Steingrover R, Prins JM, van der Kuyl AC, Cornelissen M: A sudden rise in viral load is infrequently associated with HIV-1 superinfection. J Acquir Immune Defic Syndr 2008, 47:69-73.

21. Blackard JT, Mayer KH: HIV superinfection in the era of increased sexual risk-taking. Sex Transm Dis 2004, 31:201-204.

22. Kijak GH, McCutchan FE: HIV diversity, molecular epidemiology, and the role of recombination. Curr Infect Dis Rep 2005, 7:480-488.

doi:10.1186/1743-422X-8-392

Cite this article as: Andreani et al:: Detection of HIV-1 dual infections in highly exposed treated patients. Virology Journal 2011 8:392.

\section{Submit your next manuscript to BioMed Central and take full advantage of:}

- Convenient online submission

- Thorough peer review

- No space constraints or color figure charges

- Immediate publication on acceptance

- Inclusion in PubMed, CAS, Scopus and Google Scholar

- Research which is freely available for redistribution

Submit your manuscript at www.biomedcentral.com/submit 